\title{
Sonographic Measurements of the Spleen in Relation to Height: A Prospective and Observational Study in Northwest Ethiopian Adults.
}

\author{
Yared Tekle ${ }^{1}$, Sanket Dadarao Hiware ${ }^{2}$, Abebe Muche ${ }^{3}$, Shabana Andleeb Ansari ${ }^{4}$, Rupa Chhaparwal ${ }^{5}$, Hussen Mohammed ${ }^{6}$ \\ ${ }^{1}$ Lecturer, Department of Anatomy, College of Medicine and Health Sciences, Dire Dawa University, Dire Dawa, Ethiopia, ${ }^{2}$ Assistant professor, Department of \\ Anatomy, Imam Abdulrahman Bin Faisal University, College of Medicine, Dammam, Saudi Arabia, ${ }^{3}$ Associate Professor, Department of Anatomy, College of \\ Medicine, University of Gondar, Gondar, Ethiopia, ${ }^{4}$ Demonstrator, Department of Pathology, Government Medical College, Chhindwara, Madhya Pradesh, \\ ${ }^{5}$ Associate professor, Department of Anatomy, Sri Aurobindo Institute of Medical Sciences, Indore, India. ${ }^{6}$ Lecturer, Department of Public health, College of \\ Medicine and Health Sciences, Dire Dawa University, Dire Dawa, Ethiopia.
}

\section{Abstract}

Background: Spleen size vary widely according to age, sex and region. Many diseases can affect their size, ranging from infective processes to malignant disorders. Present study is done to establish the normal range of spleen size in adults of Northwest Ethiopia to assess splenomegaly in all disease conditions affecting the spleen and to correlate the dimensions of spleen with the height. Subjects and Methods: A cross-sectional prospective study design was performed at the University of Gondar, hospital. The sonographic measurements of spleen length, width, thickness and volume were performed on 380 subjects. In addition, height of the subjects were measured using standard anthropometric technique. Age and sex were also recorded. By Pearson's product moment correlation coefficients, the relation of spleen dimensions to height was evaluated. Results: Pearson`s correlation finding indicated a moderate positive significant correlation $(\mathrm{P}<0.0001)$ between the splenic length, width, volume and body height of all the subjects $(\mathrm{r}:>0.3)$. No statistically significant correlation with splenic dimensions in males ( $r=0.107,0.039,0.060$, and 0.091 for spleen length, width, thickness, and volume, respectively) was found. Height of female study subjects had a statistically significant positive correlation with spleen length $(\mathrm{r}=0.203, \mathrm{P}<0.01)$, width $(\mathrm{r}=0.175$, $\mathrm{P}<0.05)$, thickness $(\mathrm{r}=0.292, \mathrm{P}<0.001)$, and volume $(\mathrm{r}=0.261, \mathrm{P}<0.001)$. Conclusion: The dimensions of the spleen (Length, width, thickness and volume) are found to have statistically significant positive correlation coefficient with the height of the female population.

Keywords: Spleen, dimensions, ultrasonography, height.

Corresponding Author: Dr. Sanket Dadarao Hiware, Assistant professor, Department of Anatomy, Imam Abdulrahman Bin Faisal University, College of Medicine, Dammam, Saudi Arabia.

Received: October 2018

Accepted: January 2019

\section{Introduction}

Liver and spleen size vary widely according to age. Many diseases can affect their size, ranging from infective processes to malignant disorders. ${ }^{[1,2]}$ Palpation and percussion are the standard bedside techniques to document liver and spleen size, but are far from accurate to detect small increase in size. ${ }^{[3]}$ The spleen has to be enlarged two to three times its normal size to be clinically palpable, although it may be normally palpable in $15-17 \%$ of healthy neonates and $10 \%$ of healthy children. Clinical assessment of hepatomegaly by palpation and percussion has also been shown to lack both accuracy and reliability. ${ }^{[2]}$

Ultrasonography is a non-invasive, established, safe, quick and accurate method for measurement of liver and spleen size. ${ }^{[4]}$ We conducted this study to establish standards of liver and spleen length by ultrasonography in healthy Indian children, based on age, sex and somatometric parameters, as the available literature is scarce. ${ }^{[5-8]}$

The variation in the anthropometric features of various populations, races and regions were an established fact. In the literature, the variation of normal spleen sizes among different age groups of study subjects have been reported.
The standard normal range of spleen size in the population is a prerequisite for correct interpretation. ${ }^{[9]}$

Northwest Ethiopia is an endemic zone for malaria, kalaazar and other infectious diseases affecting children as well as adults causing various ranges of splenomegaly. Hence, it is utmost important to establish the normal range of spleen size in adults of Northwest Ethiopia to assess splenomegaly in all disease conditions affecting the spleen.

\section{Subjects and Methods}

The study was done for the period of one year in the University of Gondar. The cross-sectional and prospective ultrasonic valuation of splenic sizes was done on 380 adult subjects (180 males and 200 females) [Figure 1]. Only those individuals who had normal homogenous echo pattern of the spleen, without evidence of any abnormality were involved in the study. Besides this the study subjects had normal complete blood count, white blood cell with differential, red blood cells and normal range of haemoglobin levels 12-18 gram/decilitre. The subjects having clinical or laboratory evidence of infection (fever either at the time of the examination or within at least 4 
weeks prior to the examination) were excluded from the study.

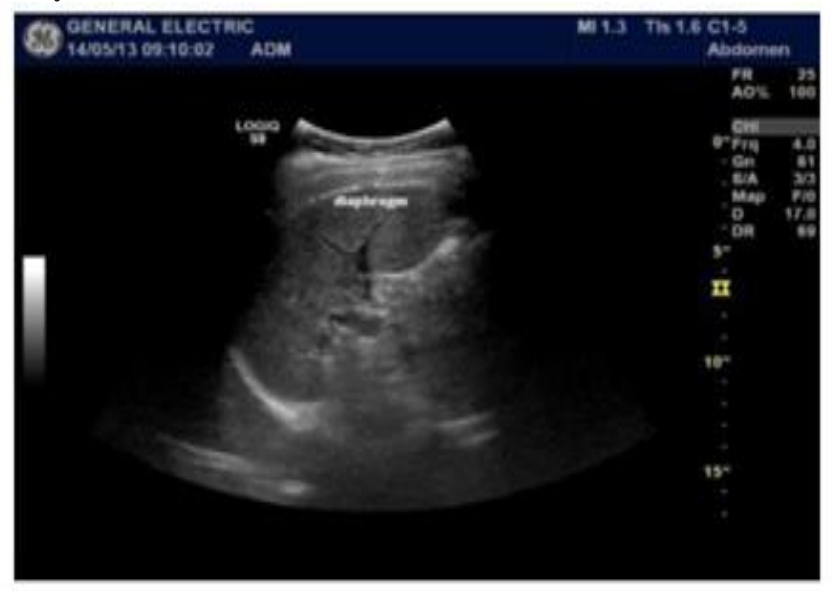

Figure 1: Normal positioned spleen, left hypocondrium. Anatomical relation with the diaphragm. ${ }^{[4]}$

The sample size was determined using the formula designed for general population by considering maximum variability within the population by taking $\mathrm{P}=0.5$

$\mathrm{n}=\mathrm{Zá} / 22 \mathrm{P}(1-\mathrm{P}) / \mathrm{d} 2$; with CI $95 \%$ and margin of error $5 \%$ $\mathrm{n}=384$ subjects

Where; $n=$ sample size

$\mathrm{z}=$ Confidence interval of $95 \%$

$\mathrm{p}=$ Proportion

$\mathrm{d}=$ Margin of error

Following radiological parameters were measured

Spleen length: Measured in longitudinal plane at hilum the maximum distance between the dome of the spleen and the splenic tip. ${ }^{[5]}$

Spleen width: Measured in a plane perpendicular to the length at hilum the maximum distance between the medial and lateral borders of the spleen. ${ }^{[5]}$

Spleen thickness: The maximum AP dimension measured on the transverse section. ${ }^{[5]}$

Volume of the spleen: length $\times$ width $\times$ depth $\times 0.524)($ The formula is frequently used for estimation of the volume of many irregularly shaped organs. $)^{[8]}$

The patients selected for the present study were examined using a Sonoscape SSI 8000 ultrasound machine (Soonchunhyang University Medical center, China) for abdominal and/or pelvic problems not related to the spleen, mostly due to abdominal pain and urinary tract infection. The study subjects had no history of disease related to the spleen and hematologic, oncologic or traumatic conditions. In addition to sonographic data, baseline data including age, gender and height were recorded for all participants. Height was measured with the help of stadiometer using standard anthropometric method. ${ }^{[7]}$

The collected data were checked for completeness, accuracy and clarity before analysis. The data were entered into a spreadsheet and analysed using the IBM SPSS Statistics, version 20. The means ( \pm standard deviation), ranges, minimum, maximum, and the $95 \%$ confidence intervals for the mean (in order to include the true population mean in $95 \%$ of the cases) were all calculated. P- Value less than 0.05 is considered as statistically significant. The coronal measurements of the spleen and the volume were compared with the height of the various subjects. Differences of continuous variables between two independent groups were assessed with the 2-tailed t-test. The relationship between splenic dimensions and height was assessed with the Pearson`s correlation coefficient (r).

\section{Results}

A total of 380 adults consisting of $47 \%$ males and $53 \%$ females were enrolled. Of the subjects, $49 \%$ and $51 \%$ were urban and rural residents, respectively. The age range of the study populations was between 18 and 80 years, with the mean age of 35.4 years $( \pm 12.2)$. The mean height for males was $163.4 \mathrm{~cm}( \pm 7.5)$ and for females was $162.8( \pm 6.4)$.

From the above [Table 1] the maximum measurement obtained for the spleen length, width, and thickness were $13.6 \mathrm{~cm}, 7.3 \mathrm{~cm}, 6.2 \mathrm{~cm}$, and volume $248.64 \mathrm{~cm} 3$, respectively.

Pearson`s correlation finding indicated a moderate positive significant correlation $(\mathrm{P}<0.0001)$ between the splenic length, width, volume and body height (r: $>0.3$ ) [Table 2].

Table 1: Sociodemographic data and anthropometric measurement of spleen size.

\begin{tabular}{|c|c|c|c|c|c|c|c|c|}
\hline & $\mathbf{N}$ & $\%$ & Age & $\begin{array}{l}\text { Height } \\
\text { (cm) }\end{array}$ & $\begin{array}{l}\text { Spleen length in cm } \\
(\text { Mean } \pm \text { SD })\end{array}$ & $\begin{array}{l}\text { Spleen width in } \\
\text { cm }(\text { Mean } \pm \text { SD) }\end{array}$ & $\begin{array}{l}\text { Spleen thickness in } \\
\text { cm }(\text { Mean } \pm \text { SD) }\end{array}$ & $\begin{array}{l}\text { Spleen volume in } \\
\text { cm3 (Mean } \pm \text { SD) }\end{array}$ \\
\hline All Gender & 380 & 100 & $35.4(12.2)$ & $163.4(7.5)$ & $9.95(1.2)$ & $4.3(.7)$ & $3.8(.8)$ & $92.0(38.4)$ \\
\hline Male & 180 & 47 & $35.9(12.2)$ & $\begin{array}{l}169.3(4.9) \\
\end{array}$ & $10.5(1.0)$ & $4.6(.9)$ & $4.0(.8)$ & $107.7(37.4)$ \\
\hline Female & 200 & 53 & $34.9(12.2)$ & $158.1(5.2)$ & $9.4(1.12)$ & $4.0(.6)$ & $3.6(.8)$ & $\begin{array}{l}78.0(33.7) \\
\end{array}$ \\
\hline Urban & 186 & 49 & $33.2(12.0)$ & $163.5(7.7)$ & $9.9(1.27)$ & $4.3(.7)$ & $3.9(.9)$ & $95.8(41.0)$ \\
\hline Rural & 194 & 51 & $37.4(12.1)$ & $163.3(7.4)$ & $9.9(1.2)$ & $4.2(.7)$ & $3.7(.8)$ & $88.4(35.6)$ \\
\hline
\end{tabular}

Table 2: Pearson`s correlation (r) of spleen dimension with height of all the subjects.

\begin{tabular}{|l|l|l|l|l|l|}
\hline \multicolumn{2}{|c|}{} & Spleen length in cm & Spleen width in cm & Spleen thickness in cm & Volume of spleen (cm3) \\
\hline \multirow{2}{*}{\begin{tabular}{l} 
Height $\mathrm{cm}$ \\
\cline { 2 - 7 }
\end{tabular}} & Pearson Correlation & 0.441 & 0.335 & 0.294 & 0.395 \\
\cline { 2 - 7 } & Sig. (2-tailed) & 0 & 0 & 0 & 0 \\
\cline { 2 - 7 } & $\mathrm{N}$ & 380 & 380 & 380 & 380 \\
\hline
\end{tabular}

Table 3: Pearson`s correlation ( $r$ ) of spleen dimension with height of male subjects.

\begin{tabular}{|l|l|l|l|l|l|}
\hline \multicolumn{2}{|c|}{} & Spleen length in cm & Spleen width in cm & Spleen thickness in cm & Volume of spleen (cm3) \\
\hline \multirow{2}{*}{$\begin{array}{l}\text { Height } \\
\text { in cm }\end{array}$} & Pearson Correlation & 0.107 & 0.039 & 0.06 & 0.091 \\
\cline { 2 - 7 } & Sig. (2-tailed) & 0.154 & 0.6 & 0.42 & 0.224 \\
\cline { 2 - 7 } & $\mathrm{N}$ & 180 & 180 & 180 & 180 \\
\hline
\end{tabular}


[Table 3] depicts that the height of the study subject had no statistically significant correlation with splenic dimensions in males $(\mathrm{r}=0.107,0.039,0.060$, and 0.091 for spleen length, width, thickness, and volume, respectively) [Table $3]$.

Table 4: Pearson`s correlation (r) of spleen dimension with height of female subjects.

\begin{tabular}{|l|l|l|l|l|l|}
\hline \multicolumn{2}{|c|}{} & $\begin{array}{l}\text { Spleen } \\
\text { length } \\
\text { in cm }\end{array}$ & $\begin{array}{l}\text { Spleen } \\
\text { width } \\
\text { in cm }\end{array}$ & $\begin{array}{l}\text { Spleen } \\
\text { thickness } \\
\text { in cm }\end{array}$ & $\begin{array}{l}\text { Volume } \\
\text { of } \\
\text { spleen } \\
\text { (cm3) }\end{array}$ \\
\hline $\begin{array}{l}\text { Height } \\
\text { in cm }\end{array}$ & $\begin{array}{l}\text { Pearson } \\
\text { Correlation }\end{array}$ & 0.203 & 0.175 & 0.292 & 0.261 \\
\cline { 2 - 6 } & $\begin{array}{l}\text { Sig. (2- } \\
\text { tailed) }\end{array}$ & 0.004 & 0.013 & 0 & 0 \\
\cline { 2 - 6 } & $\mathrm{N}$ & 200 & 200 & 200 & 200 \\
\hline
\end{tabular}

[Table 4] shows that the height of female study subjects had a statistically significant positive correlation with spleen length $\quad(r=0.203, \quad \mathrm{P}<0.01)$, width $\quad(\mathrm{r}=0.175, \quad \mathrm{P}<0.05)$, thickness $\quad(\mathrm{r}=0.292, \quad \mathrm{P}<0.001)$, and volume $(\mathrm{r}=0.261$, $\mathrm{P}<0.001)$.

\section{Discussion}

Our study revealed that the difference between male and female spleen dimensional measurements may be due to the difference in height, weight, surface area and the genetic factors.

Though ultrasonography is routinely practiced to evaluate visceral organs in adults in Ethiopia, there is no report on the splenic dimensional measurements as well as correlations of measurements with age and sex and other sociodemographic variables. Hence, the present study will provide shadow for further research.

African reports on the correlation of spleen length and height and weight of the study subjects indicated stronger correlation with the subject height than their weight. ${ }^{[1,2]}$ This finding similar to our finding the spleen length has moderate positive correlation with the subject height $(r=0.441 \mathrm{p}<0.0001)$ and the volume of spleen also has moderate positive correlation with height of subjects $(\mathrm{r}=0.395 \mathrm{p}<0.0001)$. The width of spleen has moderate positive correlation with the subject height ( $\mathrm{r}=0.335$ $\mathrm{p}<0.0001)$ and weak positive correlation with thickness $(r=0.294 \mathrm{p}<0.0001)$. These agreed with the finding of previous literatures. ${ }^{[3-5]}$ This correlation between subject height and spleen length and width of the individual may suggest that the growth of each individual is associated with an increase spleen size.

A study done on African population revealed that the mean spleen length was $8.9 \mathrm{~cm}$, width of $4.9 \mathrm{~cm}$, thickness of $5 \mathrm{~cm}$ and spleen volume $119.5 \mathrm{~cm} 3$. The mean spleen size of Africans was smaller than western population and the men spleen size was larger than women. However, correlation of splenic size with age, weight or BMI was not reported. ${ }^{[6]}$

Picardi et al. found mean longitudinal dimension of spleen ranged from 8 to $11 \mathrm{~cm}$ (median: $9.5 \mathrm{~cm}$ ). ${ }^{[11]}$ Mittal et al. performed pilot study of normal measurement of spleen by ultrasonography on Rajasthani population and found average length of spleen $9.40 \pm 0.91 \mathrm{~cm}$ in males and $9.34 \pm$ $0.95 \mathrm{~cm}$ in females. ${ }^{[12]}$ In older subjects they found mean length of spleen $9.64 \pm 0.64 \mathrm{~cm}$. Spielmann et al, average length of spleen was found to be $11.4 \pm 1.7 \mathrm{~cm}$ in males and $10.3 \pm 1.3 \mathrm{~cm}$ in females. ${ }^{[13]}$

Konus et al. found mean longitudinal dimension: $10.1 \pm$ $1.03 \mathrm{~cm} \cdot{ }^{[14]}$ In our study mean splenic length in North Indian population was $10.67 \pm 1.62 \mathrm{~cm}$ (female: $10.34 \pm$ 1.58 and male $10.91 \pm 1.67 \mathrm{~cm}, \mathrm{p}>0.05$ ). Mittal et al. measured average width of spleen in male as well as female $3.45 \pm 0.59 \mathrm{~cm}$ and $3.59 \pm 0.55 \mathrm{~cm}$ respectively. Average width of spleen measured by Spielmann was $5.0 \pm 0.8$ in males and $4.2 \pm 0.7 \mathrm{~cm}$ in females. All these dimension of spleen are best correlated with height of the patients. ${ }^{[13]}$

\section{Conclusion}

- Pearson`s correlation finding indicated a moderate positive significant correlation $(\mathrm{P}<0.0001)$ between the splenic length, width, volume and body height of all the subjects (r: $>0.3$ ).

- No statistically significant correlation with splenic dimensions in males $(\mathrm{r}=0.107,0.039,0.060$, and 0.091 for spleen length, width, thickness, and volume, respectively) was found.

- Height of female study subjects had a statistically significant positive correlation with spleen length $(\mathrm{r}=0.203, \mathrm{P}<0.01)$, width $(\mathrm{r}=0.175, \mathrm{P}<0.05)$, thickness $(\mathrm{r}=0.292, \mathrm{P}<0.001)$, and volume $(\mathrm{r}=0.261, \mathrm{P}<0.001)$.

\section{References}

1. Singh A, Chandra N, Ansari H, Das JK. Measurement of spleen width in relation with the height in the adults of Bahir. Anat Sci. 2016;24(1):13-7.

2. Spielmann AL, Delong DM, Kliewer MA. Sonographic Evaluation of Spleen Size in Tall Healthy Athletes. Am J Radiol. 2005;184(1):459 .

3. Hosey RG., Mattacola CG., Kriss V., Armsey T., Quarles JD., Jagger J. Ultrasound assessment of spleen size in collegiate athletes. $\mathrm{Br}$ J Sport Med. 2006;40(1):251-4.

4. Yahuza MA, Tabari AM, Isyaku K, Suwaid MA, Umar MU, Kabo NA. Sonographic measurement of spleen dimensions in healthy adults in North - Western Nigeria. Nij $\mathrm{J}$ Basic Clin Sci. 2016;13(1):30-5.

5. Ehimwenma O, Tagbo M. Detemination of normal dimension of the spleen by ultrasound in an endemic tropical environment. Nijer Med J. 2011;3(52):198-203.

6. Mustapha Z, Tahir A, Tukur M, Bukar M, Lee W. Sonographic determination of normal spleen size in an adult African population. Eur J Radiol. 2010;75(1):133-5.

7. Lamb PM, Lund A, Kanagasabay RR, Martin A, Webb JA, Reznek R. Spleen size: How well do linear ultrasound measurements correlate with three dimensional CT volume assessments? $\mathrm{Br}$ J Radiol. 2002;75(1):573-7.

8. Arora N, Sharma PK, Sahai A, Singh R. Sonographic measurements of the spleen in relation to age; a prospective study in north Indian adults. J Anat soc India. 2010;59(2):177-81.

9. Gangte SD, Singh NS, Singh MM, Singh WJ. Ultrasonographic Measurement of Splenic Length In Relation To Age of Adult ' $\mathrm{s}$ in Manipur. IOSR J Dent Med Sci. 2015;14(10):43-5.

10. Celiktas M, Ozandac S, Goker P, Bozkir M. Sonographic Determination of Normal Spleen Size in Turkish Adults. IntJ 
Morphol. 2015;33(4):1401-5.

11. Picardi M, Martinelli V, Ciancia R, Morante R, Sodano A, Fortunato G, Rotoli B: Measurement of spleen volume by ultrasound scanning in patients with thrombocytosis: a prospective study. (2002); 99(11):4228-30.

12. Mittal R, Chowdhary DS: A Pilot study of the normal measurement of the liver and spleen by ultrasonography in Rajasthani population. Journal of clinical and diagnostic research. (2010); 4: 2733-36.
13. Spielmann AL, Delong DM and Kliewer MA: Sonographic evaluation of spleen size in all tall healthy atheletes. AJR (2005); 184:45-49.

14. Konus OL, Ozdemir A, Akkaya A, Erbas G, Celik H, Isik S.: Normal liver, spleen and kidney dimensions in neonates, infants and children: evaluation with sonography. Am J Roentgenol. (1998); 171: 1693-98.

Copyright: () the author(s), 2019. It is an open-access article distributed under the terms of the Creative Commons Attribution License (CC BY 4.0), which permits authors to retain ownership of the copyright for their content, and allow anyone to download, reuse, reprint, modify, distribute and/or copy the content as long as the original authors and source are cited.

How to cite this article: Tekle Y, Hiware SD, Muche A, Ansari SA, Chhaparwal R, Mohammed H. Sonographic Measurements of the Spleen in Relation to Height: A Prospective and Observational Study in Northwest Ethiopian Adults. Asian J. Med. Res. 2019;8(1):AT01-AT04.

DOI: dx.doi.org/10.21276/ajmr.2019.8.1.AT1 